American Journal of Pharmacology and Toxicology 4 (2): 22-28, 2009

ISSN 1557-4962

(C) 2008 Science Publications

\title{
Effects of Leaf Extract of Urtica pilulifera L. on Male Reproductive System of Streptozotocin-Diabetic Rats
}

\author{
Fawzi Irshaid and Kamal Mansi \\ Department of Biological Sciences, Faculty of Science, Al al-Bayt University, \\ P.O. Box 130040, Al-Mafraq 25113, Jordan
}

\begin{abstract}
Problem statement: Urtica pilulifera L. (Urticaceae), has long been used for the treatment of various aliments including diabetes. Diabetes is a metabolic disorder characterized by hyperglycemia which has a deleterious effect on all systems including reproductive system of animals. Therefore, the current study was designed to investigate the effects of Urtica pilulifera on the reproductive system of diabetic rats. Approach: Forty male rats were evenly divided into four groups: Group I consisted of non-diabetic rats that received only the vehicle; group II-IV was injected intraperitonially with a single dose of streptozotocin (STZ) of $70 \mathrm{mg} \mathrm{kg}^{-1}$; groups III and IV were given methanol extract of Urtica pilulifera orally, 3 days after the STZ injection, at daily doses of 1.0 and $2.0 \mathrm{~g} \mathrm{~kg}^{-1}$, respectively. After 4 weeks of treatments, all the rats were sacrificed. Results: Administration of $70 \mathrm{mg} \mathrm{kg}^{-1}$ of streptozotocin to male rats induced diabetes and significantly reduced the body and sex organ weights, testosterone levels, sperm count and motility and significantly increased the glucose levels and water and food intake. By contrast, rats given the Uritica pilulifera methanol extract had significantly improved body weight gain, whereas the glucose levels, water and food intake significantly improved in treated diabetic male rats. In addition, this extract improved the reproductive system of the diabetic male rats by significantly increasing the testis and epididymis weights, testosterone levels, sperm count and motility. Conclusion/Recommendations: We concluded that the adverse effects of STZ-diabetes on reproductive system of male rats can be reversed by treatment with Urtica pilulifera leaf extract; and this leaf extract exhibits antihyperglycemic and spermatogenic activities. Based on these findings, we suggested the possible utilization of Urtica pilulifera extracted as a therapy to prevent the development of diabetes in later life and improved the performance of male reproductive system in animals and humans.
\end{abstract}

Key words: Antihyperglycemia, Antioxidants, Urtica pilulifera, spermatogenic activities, testosterone.

\section{INTRODUCTION}

Urtica pilulifera L. (U. pilulifera) is an annual plant from the family of Urticaceae that has been extensively cultivated in the Mediterranean region. This plant is also commonly known in Roman as Nettle and in Jordan as Qurraus ${ }^{[1,2]}$. For decades, crude extracts of plant species of $U$. pilulifera have long been used in many countries around the world as a traditional medicine for the treatment of various diseases including Diabetes Mellitus (DM) ${ }^{[3,4]}$. DM is mainly due to relatively low level of insulin production or an inability of the body to use insulin properly which, in turn, leads to hyperglycemia ${ }^{[5]}$. Hyperglycemia has been recently implicated in induction of oxidative stress which, in turn, leads to initiation and development of diabetic complications. Diabetic complications are many and include physical disability, kidney failure, visual impairment, cardiovascular disease and sexual dysfunction ${ }^{[6]}$.

The direct effects of lacking of insulin on reproductive system of male rats have been reported by several investigators ${ }^{[7,8]}$. For instance, administration of high doses of streptozotocin (STZ) to male rats leads to a decrease in Leydig cell function, testosterone production, sperm output and fertility ${ }^{[9]}$. This decrease may be the result of absence of the stimulatory effect of insulin on these cells. Other models of DM, such as the spontaneously diabetic rat also show a similar pattern of Leydig cells alternations, indicating that this process is inherent to this disease ${ }^{[10]}$. A more recent study also reported that diabetes mellitus due to insulin deficiency

Corresponding Author: Fawzi Irshaid, Department of Biological Sciences, Faculty of Science, Al al-Bayt University, P.O. Box 130040, Al-Mafraq 25113, Jordan

Tel: 00962776948182/ 962-2-6297000/Ext: 2120 Fax: 0096265151261 
appears to have adverse effects on sex organs in men ${ }^{[11]}$. Thus, any changes in the level of insulin could be correlated with the function and growth of the testes.

It is important to note that some medicinal plants that were commonly used for the treatments of DM are linked to male infertility, such as Azadirachta indica (Meliaceae) and Quassia amara (Simaroubaceae) ${ }^{[12-14]}$. By contrast, administration of Hibiscus macrocanthus (Malvaceae) and Basella alba (Basellaceae) extracts caused an increase in the serum levels of testosterone and in the weight of the rat testis ${ }^{[15]}$. However, despite of widespread use of $U$. pilulifera as folk medicine to control DM and other ailments, its impacts on the reproductive system has not been reported. Furthermore, it is important to note that administration of STZ in rats provides a good model to study reproductive defect, because STZ-induced diabetic rats exhibit a number of defects in reproductive organs that resemble those seen in diabetic humans. Therefore, the present study was undertaken to evaluate the effects of methanol extract of $U$. pilulifera on diabetes induced male rat's reproductive structures and functions, such as sperm motility and count, sex organ weights and testosterone secretion.

\section{MATERIALS AND METHODS}

Plant collection and preparation of extraction: $U$. pilulifera leaves were collected from Sail Husban, Nauor, Jordan at different times from April to June 2008. The plant was authenticated by Professor Jamil Lahham, Taxonomist, at the herbarium of the Department of Biological Sciences, Faculty of Science, Yarmouk University, Irbid, Jordan. The voucher specimen (NO.AHE-3-007) was deposited in the Department of Biological Science, Faculty of Science, Al al-Bayt University, Al-Mafraq, Jordan.

Leaves of $U$. pilulifera were air-dried in shaded well-ventilated area and then ground into fine powder. The powder $(350 \mathrm{~g})$ was placed on a Soxhlet cold extractor using absolute methanol as solvent and remained for three consecutive days ${ }^{[16]}$. The extract was concentrated to dryness in rotary evaporator under reduced pressure and controlled temperature $\left(45^{\circ} \mathrm{C}\right)$ to yield an $11.4 \%$ viscous greenish-colored extract. The extract was kept at $4{ }^{\circ} \mathrm{C}$ in a glass container until use.

Experimental animals and preparation of doses: Male Wister rats weighing 160-185 g were initially used for this study. All rats were obtained from the animal house of the Jordan University of Science and Technology, Irbid, Jordan. The rats were harbored in stainless steel cages under standard laboratory condition of $12 \mathrm{~h} \mathrm{light/dark}$ cycle throughout the experimental periods. They had access to food (top fed, Sapele) and water ad libitum. The animals were carefully checked and monitored every day for any changes.

After the $\mathrm{LD}_{50}$ was determined, two doses, 1.0 and $2.0 \mathrm{~g} \mathrm{~kg}^{-1}$ of body weight, were selected and used in this study. The two doses were prepared by dissolving an appropriate amount of this viscous extract in $10 \mathrm{~mL}$ Tween-20: $0.9 \% \mathrm{NaCl}(1: 9, \mathrm{~V} / \mathrm{V})$. The vehicle was obtained by dissolving $1 \mathrm{~mL}$ of Tween-20 in $9 \mathrm{~mL}$ of $0.9 \% \mathrm{NaCl}$.

Induction of diabetes: To induce diabetes, male rats were first anesthetized with inhalation of gaseous nitrous. STZ was purchased from Sigma Company (St Louis, MO, USA) and was prepared in freshly citrate buffer (0.1 M, pH 4.5). The STZ solution was injected intraperitonially at a concentration of $70 \mathrm{mg} \mathrm{kg}^{-1}$ of body weight in a volume of $1 \mathrm{~mL} \mathrm{rat}^{-1}{ }^{[8]}$. After the STZ injection, the rats were given a $5 \%$ glucose solution for $48 \mathrm{~h}$ and then were subjected to overnight fasting. After measuring fasting blood sugar, diabetic status was determined. Rats with blood glucose of $250 \mathrm{mg} \mathrm{dL}^{-1}$ or more were classified as diabetic rats and were used for the subsequent experiments. Non-diabetic controls were injected with citrate buffer $\left(0.5 \mathrm{~mL} \mathrm{~kg}^{-1}\right.$ body weight $)$ instead of STZ.

Experimental design: Forty rats were assigned to four experimental groups of 10 rats each. Group I consisted of non-diabetic rats that received only vehicles $\left(0.5 \mathrm{~mL} \mathrm{~kg}^{-1}\right.$ body weight) and served as control group. Group II consisted of diabetic rats that received only vehicles $\left(0.5 \mathrm{~mL} \mathrm{~kg}^{-1}\right.$ body weight). Group III and IV consisted of diabetic rats that were treated with $1.0 \mathrm{~g} \mathrm{~kg}^{-1}$ (Group III) or $2 \mathrm{~g} \mathrm{~kg}^{-1}$ (Group IV) of the methanol $U$. pilulifera extract. Treatments were administrated every day by intragastric gavage. Rats were maintained in these treatment regimens for four weeks with free access to food and water ad libitum. These experiments complied with the guidelines of our animal ethics committee which was established in accordance with the internationally accepted principles for laboratory animal use and care. Daily measurements of body weight and food and water intake were recorded.

Blood and organs collecting: Blood sample was collected every week from each animal. Part of the blood sample was used for glucose analysis. The remaining blood sample was put into sterile tubes and allowed to clot for $30 \mathrm{~min}$ and centrifuged at $4000 \mathrm{rpm}$ for $10 \mathrm{~min}$ using a bench top centrifuge. Serum was 
collected and kept at $-20^{\circ} \mathrm{C}$ for hormone determination. At the end of the experimental period, each rat was reweighed and starved for $24 \mathrm{~h}$. Then, blood sample was collected from each animal by cardiac puncture and rats were sacrificed by cervical dislocation under light ether anesthesia. Epididymis and testes were carefully dissected out and rinsed in cold saline solution, weighed and processed immediately as described below.

Glucose and testosterone determination: Glucose was measured by the glucose oxidase method using a commercially available kit (glucose (HK) assay kit, Sigma-Aldrich). All plasma samples were assayed for testosterone using enzyme-linked immunoassay methodology (ELISA) and the absorbency was read at $450 \mathrm{~nm}$ as described previously ${ }^{[17]}$. The ELISA kits were obtained from Dia Metra (Italy).

Assessment of sperm count and motility: The organ weights for epididymis and testes were recorded for each rat. The sperm motility and count were determined. Sperm count was conducted according to the method of Dills et al. ${ }^{[18]}$. Briefly, the right testis was cut into very fine pieces using a scalpel and homogenized for $20 \mathrm{~min}$ in $50 \mathrm{~mL}$ of STM solution containing $0.9 \mathrm{NaCl}, 0.05 \%$ Triton $\mathrm{X}-100$ and $0.01 \%$ merthiolate. Four separate hemocytometer slides were made and the testis sperms were counted under light microscopy with the use of a manual counter.

The left testis was also taken and minced by a sharp blade and immersed in $1 \mathrm{~mL}$ of physiological saline and the solution was kept in $37^{\circ} \mathrm{C}$. After gentle mixing, a drop of the solution was taken on Neubaur chambers counting and then each was assessed for sperm motility ${ }^{[19]}$. This was done by counting motile and non-motile sperm in different fields and was expressed as a percentage. All the solutions and instruments that were used in this experiment were kept in an incubator at $37^{\circ} \mathrm{C}$.

Statistical analysis: Data are presented as means \pm SD. Student' t-test analysis was applied to test the significance of differences between the results of the treated, untreated and control groups. The difference was considered significant at the conventional level of significance $(\mathrm{p}<0.05)$.

\section{RESULTS}

Effect on body weight of male rats: To determine the effect of treatment of $U$. pilulifera extract on body weight in the STZ-treated rats, all rats were monitored for gain in body weight. The control group (I) gained weight over the four weeks of experimental period, with the mean body weight increasing by $48 \mathrm{~g}$ after 4 weeks (Table 1). In contrast, the untreated diabetic group (II) lost an average of $19 \mathrm{~g}$ after 4 weeks $(\mathrm{p}<0.05)$. Treatment with $U$. pilulifera resulted in significant weight gain to levels approaching the control group (Groups III and IV, versus Group I).

Effect on water and food intake: Water and food intake in untreated diabetic group were significantly higher than that of the control group (Table 2 and 3). On other hand, there were significant decreases in water and food intake in treated diabetic groups compared to untreated diabetic group during the entire period of the experiment $(\mathrm{p}<0.05)$. The two treated diabetic groups also consumed more food when compared to control group during the entire study period.

Table 1: Effect of oral administration of $U$. pilulifera extract for four weeks on body weight $(\mathrm{g})$ in STZ-diabetic male rats

\begin{tabular}{|c|c|c|c|}
\hline \multirow[b]{2}{*}{ Group } & \multicolumn{2}{|c|}{ Body weight (g) } & \multirow{2}{*}{$\begin{array}{l}\text { Gain in } \\
\text { body } \\
\text { weight }(\mathrm{g})\end{array}$} \\
\hline & Initial & 4 weeks & \\
\hline I (control rats) & $167 \pm 7.2$ & $215 \pm 10.8$ & 48 \\
\hline II (diabetic rats) & $180 \pm 9.3$ & $161 \pm 12.1^{*}$ & -19 \\
\hline III (treated diabetic rats) & $183 \pm 8.6$ & $203 \pm 11.5 * *$ & 20 \\
\hline IV (treated diabetic rats) & $174 \pm 6.5$ & $203 \pm 14.6 * *$ & 29 \\
\hline
\end{tabular}

Table 2: Effect of oral administration of $U$. pilulifera extract for four weeks on water intake $\left(\mathrm{mL} \mathrm{day}^{-1}\right)$ in STZ-diabetic male rats Water intake $\left(\mathrm{mL} \mathrm{day}^{-1}\right)$

\begin{tabular}{llccc} 
Group & First week & Second week & Third week & Fourth week \\
\hline I & $19.4 \pm 4.2$ & $25.4 \pm 5.3$ & $17.4 \pm 6.6$ & $24.4 \pm 4.4$ \\
II & $126.6 \pm 11.5$ & $117.5 \pm 10.3^{*}$ & $122.9 \pm 11.4^{*}$ & $115.8 \pm 8.7^{*}$ \\
III & $106.4 \pm 9.6$ & $102.7 \pm 6.6^{* *}$ & $97.9 \pm 10.4^{* *}$ & $85.7 \pm 9.6^{* *}$ \\
IV & $107.3 \pm 6.6$ & $103.5 \pm 9.4^{* *}$ & $96.4 \pm 7.0^{* *}$ & $77.3 \pm 8.5^{* *}$ \\
\hline
\end{tabular}

Values are the mean values \pm standard deviation of 10 rats; *: Statistically significant when compared to control group (I) at $\mathrm{p}<0.05$; **: Statistically significant when compared to untreated diabetic group at $\mathrm{p}<0.05$

Table 3: Effect of oral administration of $U$. pilulifera extract for four weeks on food intake $\left(\mathrm{g} \mathrm{day}^{-1}\right)$ in STZ-diabetic male rats

\begin{tabular}{lllll}
\hline & \multicolumn{4}{c}{ Food intake $\left(\mathrm{g} \mathrm{day}^{-1}\right)$} \\
Group & First week & Second week & Third week & Fourth week \\
\hline I & $11.4 \pm 4.2$ & $14.5 \pm 3.5$ & $13.4 \pm 4.6$ & $12.4 \pm 3.4$ \\
II & $27.5 \pm 3.9^{*}$ & $26.0 \pm 4.8^{*}$ & $28.2 \pm 5.7^{*}$ & $25.3 \pm 4.1^{*}$ \\
III & $15.3 \pm 4.4^{* *}$ & $21.2 \pm 4.4^{* *}$ & $18.7 \pm 3.3^{* *}$ & $20.2 \pm 2.7^{* *}$ \\
IV & $17.2 \pm 2.6^{* *}$ & $20.2 \pm 4.0^{* *}$ & $20.5 \pm 2.4^{* *}$ & $18.3 \pm 3.0^{* *}$ \\
\hline
\end{tabular}

Values are the mean values \pm standard deviation of 10 rats; *: Statistically significant when compared to control group (I) at $\mathrm{p}<0.05$; **: Statistically significant when compared to untreated diabetic group at $\mathrm{p}<0.05$ 
Am. J. Pharm. \& Toxicol., 4 (2): 22-28, 2009

Table 4: Effect of oral administration of $U$. pilulifera extract for four weeks on serum glucose concentration $\left(\mathrm{mg} \mathrm{dL}^{-1}\right)$ in STZdiabetic male rats

Serum glucose concentration $\left(\mathrm{mg} \mathrm{dL}^{-1}\right)$

\begin{tabular}{lccc} 
& & & \\
Group & First week & Third week & Fourth week \\
\hline I & $83.8 \pm 16.2$ & $87.8 \pm 14.6$ & $79.4 \pm 13.2$ \\
II & $349.7 \pm 28.5^{*}$ & $352.7 \pm 32.7^{*}$ & $357.6 \pm 37.2^{*}$ \\
III & $299.5 \pm 20.6^{* *}$ & $265.2 \pm 26.6^{*}$ & $251.5 \pm 25.4^{* *}$ \\
IV & $279.4 \pm 17.0^{* *}$ & $252.5 \pm 28.4^{*}$ & $231.3 \pm 23.5^{* *}$ \\
\hline V
\end{tabular}

Values are the mean values \pm standard deviation of 10 rats; *: Statistically significant when compared to control group (I) at $\mathrm{p}<0.05$; **: Statistically significant when compared to untreated diabetic group (II) at $\mathrm{p}<0.05$

Table 5: Effect of oral administration of $U$. pilulifera extract for four weeks on serum testosterone level $\left(\mathrm{ng} \mathrm{mL}^{-1}\right)$ in STZdiabetic male rats

\begin{tabular}{llll}
\hline & \multicolumn{2}{l}{ Serum testosterone levels $\left(\mathrm{ng} \mathrm{mL}^{-1}\right)$} & \\
Group & Day 0 & Third week & Fourth week \\
\hline I & $0.732 \pm 0.045$ & $0.754 \pm 0.162$ & $0.755 \pm 0.092$ \\
II & $0.745 \pm 0.112$ & $0.288 \pm 0.056^{*}$ & $0.226 \pm 0.033^{*}$ \\
III & $0.738 \pm 0.110$ & $0.468 \pm 0.109^{* *}$ & $0.536 \pm 0.051^{* *}$ \\
IV & $0.741 \pm 0.063$ & $0.561 \pm 0.077^{* *}$ & $0.631 \pm 0.081^{* *}$ \\
\hline
\end{tabular}

Values are the mean values \pm standard deviation of 10 rats; *: Statistically significant when compared to control group (I) at $\mathrm{p}<0.05$; **: Statistically significant when compared to untreated diabetic group (II) at $\mathrm{p}<0.05$

The average food intake of treated diabetic group (II) and (III) were 18.3 and $20.2 \mathrm{~g}$, respectively, whereas that of control group was $12.4 \mathrm{~g}$ at the end of the experimental period (Table 2). These increases in food intake among treated groups (III and IV) were statistically significant when compared with that of the control group $(p<0.05)$. Along the same line (Table 3$)$, the average water intake of group (II) and (III) were 77.3 and $85.7 \mathrm{~mL} \mathrm{day}^{-1}$, respectively, at the end of the experimental period, which was significantly more than in the control group, which was $24.4 \mathrm{~mL}^{\text {day }}{ }^{-1}$.

Effect on serum glucose concentration: An increase in serum glucose concentration $\left(\mathrm{mg} \mathrm{dL}^{-1}\right)$ was recorded in untreated diabetic group, relative to the control group (Table 4). After four weeks, the serum glucose concentration in untreated diabetic group increased to $357.6 \mathrm{mg} \mathrm{dL}^{-1}$. In treated diabetic rats (Groups III/IV), the serum glucose concentration increased to 251.5 and $231.3 \mathrm{mg} \mathrm{dL}^{-1}$, respectively, after four weeks, which was significantly less than in the untreated diabetic group $(\mathrm{p}<0.05)$.

Effect on serum level of testosterone: The diabetic rats experienced a decrease in serum testosterone levels, to $62 \%$ of the levels of the control rats at the third week and $71 \%$ at the fourth week (Table 5). Treatment of the diabetic rats with $U$. pilulifera (Groups III/IV) caused a significant increase in the levels of testosterone in a dose-dependent manner $(\mathrm{p}<0.05)$.
Table 6: Effect of oral administration of U. pilulifera extract after 4 weeks on testis and epididymis weights, sperm count and motility in STZ-diabetic male rats

\begin{tabular}{|c|c|c|c|c|}
\hline \multirow[b]{2}{*}{ Parameters } & \multicolumn{3}{|c|}{ Group } & \multirow[b]{2}{*}{ IV } \\
\hline & I & II & III & \\
\hline Testis wt (g) & $1.493 \pm 0.241$ & $0.877 \pm 0.186^{*}$ & $1.203 \pm 0.103 * *$ & $1.442 \pm 0.134 * *$ \\
\hline Epididymis wt (g) & $0.677 \pm 0.184$ & $0.265 \pm 0.052^{*}$ & $0.582 \pm 0.155^{* *}$ & $0.643 \pm 0.155^{* *}$ \\
\hline Sperm count $\times 10^{6}$ & $43.20 \pm 6.600$ & $16.40 \pm 4.7 *$ & $25.20 \pm 6.700^{* *}$ & $29.20 \pm 3.600 * *$ \\
\hline Sperm motility (\%) & $83.50 \pm 7.600$ & $22.40 \pm 10.7 *$ & $66.20 \pm 7.900 * *$ & $74.40 \pm 6.400 * *$ \\
\hline \multicolumn{5}{|c|}{$\begin{array}{l}\text { Values are the mean values } \pm \text { standard deviation of } 10 \text { rats; } \\
* \text { : Statistically significant when compared to control group (I) at } \\
\text { p }<0.05 \text {; **: Statistically significant when compared to untreated } \\
\text { diabetic group (II) at } \mathrm{p}<0.05\end{array}$} \\
\hline
\end{tabular}

Effect on sex organ weights, sperm count and motility of male rats: The data in Table 6 shows that the testes and epididymis weights of the untreated diabetic group were significantly lowered at the fourth week by 41.3 and $60.9 \%$, respectively, as compared with those of the control group $(\mathrm{p}<0.05)$. Treatment of the diabetic male rats with $U$. pilulifera (Groups III/IV) caused a significant increase in testis and epididymis weights $(p<0.05)$. Along the same line, sperm count and motility of untreated diabetes group also significantly lowered, as compared with those of the control group. This reduction was statistically significant $(\mathrm{p}<0.05)$. On other hand, administration of $U$. pilulifera methanol extract for 4 weeks showed a significant improvement in the sperm count and motility of treated diabetic groups (Groups III/IV) in a dose-dependent manner $(p<0.05)$. However, the sperm count and motility of the treated diabetic groups (III and IV) were still lower than those of control group I.

\section{DISCUSSION}

Insulin is well known as an anabolic hormone that plays a vital role in maintenance of body growth and overall body metabolism. Partial or complete insulin deficiency in diabetic humans as well as in induceddiabetic experimental animals appears to have adverse effects on all organs, including reproductive organs $^{[9,11,20]}$. This present study was amid to evaluate the effects of methanol extract of $U$. pilulifera on reproductive organs of STZ-induced diabetes male rats. Our current data indicate that blood glucose level, water and food intake significantly increased, but body weight gain decreased after injection of STZ in male rats. These findings are consistent with previous study which indicated that the cytotoxic action of STZ is mediated by the formation of free radicals such as superoxide and hydroxyl radicals ${ }^{[8,21-23]}$. The action of these free radicals can cause rapid destruction of $B$-cells of pancreas, resulting in partial or complete loss of insulin production and leading to the development of hyperglycemia and its complications. These changes 
are also the normal effect of diabetes mellitus. Furthermore, our results also showed that administration of $U$. pilulifera extract resulted in lowering of blood glucose level, water and food intake significantly and improving body weight gaining in a dose-dependent manner in diabetic male rats with no apparent side effect. This confirms the study of Kavalali et al $^{[3]}$ who reported that a significant antidiabetic effect was observed in STZ-diabetic rats at the dose of $100 \mathrm{mg} \mathrm{kg}^{-1}$ of lectin isolated from U. pilulifera after administration for 30 days. However, the mechanism of action of this compound has not been reported.

Furthermore, our study also shows that injection of male rats with STZ compound reduced weights of testis and epididymis, testosterone production and sperm motility and count, suggesting a toxic effect of STZ in the structural and functional integrity of testicular tissues. Our results are in agreement with previous published reports which revealed that induction of diabetes by high doses of STZ in male testes lead to reduction in testosterone production, suggesting a decrease in the function of both Leydig (testosterone producing cell) and Sertoli (spermatogenesis), which might be caused by a reduction in insulin secretion ${ }^{[7,9]}$. An early study also indicated that glucose oxidation and utilization are important means by which spermatozoa derives energy for their motility ${ }^{[24]}$. Taken together, the negative impact of STZ on reproductive organ of male rats in this study probably can be explained by a reduction in insulin secretion, leading to development of hyperglycemia as suggested above. This notion is consistent with and supported by other studies which reported that hyperglycemia induces oxidative stress, can cause inactivation of antioxidant defense enzymes and increase production of free radicals and such conditions result in increase glycosylation and oxidation of proteins and membrane dysfunction of target cells, especially the $\beta$-cells of pancreas ${ }^{[25,26]}$.

Interestingly, our current study also shows for the first time that oral administration of $U$. pilulifera extract for four weeks improved the production of testosterone, weights of testis and epididymis, sperm motility and count in STZ-diabetic male rats. Recently, methanol extract of different parts of $U$. pilulifera extracts were found to exhibit powerful antioxidant activity against various oxidative systems in vivo ${ }^{[27]}$. The antioxidant activity of these extracts has been attributed to the reduction of lipid peroxidation and elevation of antioxidant enzyme activities. Additionally, recent studies also indicated that treatment with antioxidant compounds isolated from natural products may be important for B-cell function and growth, reducing the complications of diabetes by inhibiting the formation of free radicals in induced-diabetic animals ${ }^{[22,23]}$. Taken together, our results combined with those of previous findings allow us to suggest that the leaf extract of $U$. pilulifera contains bioactive compounds with antioxidant activities which might reverse the toxic action of STZ and thus restoring $\beta$-cell integrity and metabolic function which are responsible for synthesis of insulin. However, it is also important to note that our data lack direct evidence that links free radical inhibition to the improvement of function and growth of $\beta$-cells of pancreas and reproductive cells of diabetic male rats. In addition, these positive effects are probably due to the presence of bioactive compounds with antidiabetic and/or insulinomimetic activity resulting in an increase in glucose utilization and metabolism in peripheral tissues as reported by Kavalali et $a l \cdot{ }^{[3]}$. We can not also exclude the possibility that these bioactive compounds might cause glucose level to normalize and/or drive glucose metabolism by some other unknown mechanisms. Such mechanisms may result in reduction of hyperglycemia which might lead to resolution of the other down-stream pathologic effects. Therefore, additional experiments will be needed to characterize the details of the mechanism(s) by which $U$. pilulifera normalize the glucose level and/or affects the function and growth of both pancreas and reproductive organs of diabetic male rats.

\section{CONCLUSION}

In conclusion, the present study indicates that administration of STZ in rats induces hyperglycemia and exhibits a number of defects in reproductive organs of male rats. On other hand, methanol extract of $U$. pilulifera exhibits antihyperglycemic and spermatogenic activities in STZ-induced diabetic male rats. These activities are responsible, at least partly, for these improvements that have been seen in the performance of male reproductive system of diabetic rats. In addition, these findings suggest the possible utilization of $U$. pilulifera extract as a therapy to prevent the development of diabetes in later life and improve the performance of male reproductive system in animals and humans.

\section{ACKNOWLEDGMENT}

This research has been partially supported by grants 2008/4419 from the Deanship of Scientific Research at Al al-Bayt University. The authors would, therefore, like to appreciate the financial assistance and express our gratitude to the University. 


\section{REFERENCES}

1. Afif, F.U. and B. Abu-Irmaileh, 2000. Herbal medicine in Jordan with special less commonly used medicinal herbs. J. Ethnopharmacol., 72: 101-110. DOI: $10.1016 / \mathrm{S} 0378-8741(00) 00215-4$

2. Ali-Shtayeh, M.S., Z. Yaniv and J. Mahajna, 2000. Ethnobotanical survey in the Palestinian area: A classification of the healing potential of medicinal plants. J. Ethnopharmacol., 73: 221-232. http://www.ncbi.nlm.nih.gov/pubmed/11025160.th nobotanical+survey+in+the+Palestinian+area\&cd= $3 \& \mathrm{hl}=\mathrm{ar} \& \mathrm{ct}=\mathrm{clnk} \& \mathrm{gl}=\mathrm{jo}$

3. Kavalali, G., H. Tuncel, S. Goksel and H.H. Hatemi, 2003. Hypoglycemic activity of Urtica pilulifera in streptozotocin-diabetic rats. J. Ethnopharmacol., 84: 241-245. DOI: 10.1016/S0378-8741(02)00315-X

4. Lopatkin, N., A. Sivkov, C. Walther, S. Schlafke, A. Medvedev, J. Avdeichuk, G. Golubev, K. Melnik, N. Elenberger and U. Engelmann, 2005. Long-term efficacy and safety of a combination of sabal and Urtica pilulifera extract for lower urinary tract symptoms: A placebo-controlled, double-blind, multi-center trial. World J. Urol., 12: 742-749. http://www.plantoils.in/a_z/n/nettle_oil/nettle_oil.html

5. Narayan, K.M., J.P. Boyle, T.J. Thompson, S.W. Sorensen and D.F. Williamson, 2003. Lifetime risk for diabetes mellitus in the United States. J. Am. Med. Assoc., 290: 1884-1890. http://www.ncbi.nlm.nih.gov/pubmed/14532317

6. Engelgau, M.M., L.S. Geiss, J.B. Saaddine, J.P. Boyle, and S.M. Benjamin et al., 2004. The evolving diabetes burden in the United States. Ann. Inter. Med., $\quad 140$ : $945-950 . \quad$ DOI: 10.1136/bmj.325.7370.916

7. Hurtado De Catalfo, G., I. Nelva and T. De Gomez Dumm, 1998. Lipid dismetabolism in Leydig and Sertoli cells isolated from streptozotocin-diabetic rats. Cell Biol., 30: 1001-1010. DOI: 10.1016/S1357-2725(98)00055-7

8. Suthagar, E., S. Soudamani, S. Yuvaraj, A.K. Ismail, M.M. Aruldhas and K. Balasubramanian, 2009. Effects of streptozotocin (STZ)-induced diabetes and insulin replacement on rat ventral prostate. Biomed. Pharmacother., 63: 43-50. DOI: 10.1016/j.biopha.2008.01.002

9. Ballester, J., M.C. Munoz, J. Dominguez, M. Sensat, T. Rigaut, J.J. Guinovart and J.E. Rodriguez-Gil, 2004. Insulin-dependent diabetes affects testicular function by FSH- and LH-linked mechanisms. J. Androl., 25: 706-719. DOI:10.1038/sj.ijir.3901391
10. Murray, F.T., D.F. Cameron and J.M. Orth, 1983. Gonadal dysfunction in the spontaneously diabetic BB rat. Metabolism, 32: 141-147. http://www.ncbi.nlm.nih.gov/pubmed/2260654?do $\mathrm{pt}=\mathrm{Abstract}$

11. Agbaje, I.M. , D.A. Rogers, C.M. McVicar, N. McClure, A.B. Atkinson, C. Mallidis and S.E.M. Lewis, 2007. Insulin dependant diabetes mellitus: Implications for male reproductive function. Hum. Reprod., $\quad 22$ : $\quad 1871-1871 . \quad$ DOI: 10.1093/humrep/dem077

12. Khillare, B. and T.G. Shrivastav, 2003. Spermicidal activity of Azadirachta indica (neem) leaf extract. Contraception, 68: 225-229. DOI: 10.1016/S0010-7824(03)00165-3

13. Raji, Y. and A.F. Bolarinwa, 1997. Antifertility activity of Quassia amara in male rats in vivo study. Life Sci., 64: 1067-1074. DOI: 10.1016/S0024-3205(97)00615-2

14. Raji, Y., U.S. Udoh, O.O. Mewoyeka, F.C. Ononye and A.F. Bolarinwa, 2003. Implication of reproductive endocrine malfunction in male antifertility efficacy of Azadirachta indica extract in rats. Afr. J. Med. Sci., 32: 159-165. http://www.ncbi.nlm.nih.gov/pubmed/15032463

15. Moundipa, F.P., P. Kamtchouing, N. Koueta, J. Tantchou, N.P. Foyang and F. Mbiapo, 1999. Effects of aqueous extracts of Hibiscus macrocanthus and Basella alba in mature rat testis function. J. Ethnopharmacol., 65: 133-139. DOI: 10.1016/S0378-8741(98)00207-4

16. Sadki, G., M.A. Gafur, M.S.A. Bhyuiyan, A.H.M. Khurshid, M.H.U. Biswas, M.O.F. Hassan and A.K.A. Chowdhury, 2001. Antifertility activity of Pergularia daemia. Sciences, 1: 22-24. http://www.scialert.net/qredirect.php?doi=jms.200 1.22.24\&linkid $=$ pdf

17. Kassem, A., A. Al-Aghbari, M. AL-Habori and M. Al-Mamary, 2006. Evaluation of the potential antifertility effect of fenugreek seeds in male and female rabbits. Contraception, 73: 301-306. DOI: 10.1016/j.contraception.2005.08.020

18. Dills, W.L., W.E. Berndtson, T.R. Covey and P.B. Kingsleyhickman, 1986. Dietary potentiation of the antifertility effects of 5-thio-glucose in male rats. J. Nutr., 116: 900-915. http://jn.nutrition.org/cgi/reprint/116/5/900.pdf

19. Centola, G.M., 1996. Comparison of manual microscopic and computer-assisted methods for anaylsis of sperm count and motility. Arch. Androl., 36: 1-7. http://www.ncbi.nlm.nih.gov/pubmed/8824662 
20. Clark, M.G. and M.G. Wallis, 2003. Blood flow and muscle metabolism: a focus on insulin action. Am. J. Physiol. Endocrinol. Metabol., 284: 241-58. http://www.ncbi.nlm.nih.gov/pubmed/12531739?d opt=Abstract

21. Szudelski, T., 2001. The mechanism of alloxan and streptozotocin action in $\beta$ cells of the rat pancreas. Physiol. Res., 50: 536-546. DOI: 10.1016/j.jep.2007.10.038

22. Coskun, O., M. Kanter, A. Korkmaz and S. Oter, 2005. Quercetin, a flavonoid antioxidant, prevents and protects streptozotocin-induced oxidative stress and cell damage in rat pancreas. Pharmacol. Res., 51: 117-123. DOI: 10.1900/RDS.2007.4.33

23. Orhan, D.D., M. Aslan, N. Sendogdu, F. Ergun and E. Yesilada, 2005. Evaluation of the hypoglycemic effect and antioxidant activity of three Viscum album subspecies (European mistletoe) in streptozotocin-diabetic rats. J. Ethnopharmacol., 98: 95-102.

http://www.ncbi.nlm.nih.gov/pubmed/15763369
24. Atkinson, M.A. and N.K. Maclaren, 1994. The pathogenesis of insulin dependent diabetes. N. Engl. J. Med., 331: 1428-1436. http://www.ncbi.nlm.nih.gov/pubmed/3525287?do $\mathrm{pt}=$ Abstract

25. Penckofer, S., D. Schwertz and K. Florczak, 2002. Oxidative stress and cardiovascular disease in type 2 diabetes: The role of antioxidants and prooxidants. J. Cardiovasc. Nurs., 16: 68-85. http://www.ncbi.nlm.nih.gov/pubmed/11800069

26. Rahimi, R., S. Nikfar, B. Larijani and M. Abdollahi, 2005. A review on the role of antioxidants in the management of diabetes and its complications. Biomed. Pharmacother., 59: 365-373. http://cat.inist.fr/?aModele $=$ afficheN\&cpsidt $=17055748$

27. Mahmoud, A.H., H.M. Motawa, H.E. Wahba and A.Y. Ebrahim, 2006. Study of some antioxidant parameters in mice livers affected with Urtica pilulifera extracts. Trends Med. Res., 1: 67-74. http://www.scialert.net/qredirect.php?doi=ajb.2006 $.67 .74 \&$ linkid $=$ pdf 